\title{
Laparoscopic myomectomy: A retrospective analysis of 432 cases
}

\author{
Madhuka Rajakaruna*, Dhammike Silva, Supun Adeesha, Rukshani Edirisinghe \\ Department of Gynaecology and Obstetrics, Colombo South Teaching Hospital, Sri Lanka \\ *Corresponding Author
}

\begin{abstract}
Method: This is a retrospective study to analyzed data from 432 women who had undergone laparoscopic myomectomy at Colombo south teaching Hospital, Sri Lanka during the period of 10 years
\end{abstract}

Results: Mean age of the population was 35.5 years (SD 6.083) and majority were nulliparous (67\%). Single fibroid found in 168 patients $(38.9 \%)$, fibroids $2-4$ found in 199 patients $(46.1 \%)$ and fibroids 5-10 found in 65 patients $(15 \%)$. Mean blood loss was $159.4+/-68.03 \mathrm{ml}$ while mean operative time was $124+/-49.6$ minutes. Mean operative time is $\mathbf{9 2 . 2 3}$ minute for fibroid size less than $8 \mathrm{~cm}$ vs 178.9 minute for fibroid more than $12 \mathrm{~cm}$. Mean blood is $115.25 \mathrm{ml}$ for fibroid less than $8 \mathrm{~cm}$ vs $238.27 \mathrm{ml}$ for fibroid size more than $12 \mathrm{~cm}$. Mean operative time and blood loss are increased with posterior wall and broad ligament fibroids . However it is not statistically significant ( $P$ Value 0.006 and 0.008 respectively) . Prolonged operative time did not impact on surgical out comes in terms of hospital stay and blood transfusion.

Conclusion: In experienced and expert hand, laparoscopic myomectomy is a safer procedure with good surgical out comes and low complication rate. Operative time and blood loss mainly associated with size of largest fibroid and number of fibroids. Open myomectomy may be benefit for number of fibroids $>10$ when considering completeness of surgery. Hand morcellation through suprapubic port is a safe and effective method of specimen retrieval in laparoscopic myomectomy.

Key words: Laparoscopic myomectomy, Surgical outcomes, Morcellation

\section{INTRODUCTION}

$\mathrm{L}$ aparoscopic Myomectomy is a challenging yet rewarding gynaecological surgery conducted worldwide by skilled laparoscopic surgeons. Colombo-South Teaching Hospital $(\mathrm{CSTH})$ is the centre of excellence in Gynaecology Laparoscopic Surgeries in Sri Lanka and lead by an experienced surgeon who has got more than 15 years of hands-on advanced gynaecological laparoscopic surgeries in Sri Lanka. Fibroids are benign hormone sensitive monoclonal tumours that could grow into a range of a few millimetres to a massive mass in 20 to $30 \%$ of women in reproductive age group ${ }^{\mathrm{I}, \mathrm{II}}$. Uterine leiomyomas can be debilitating to women not only in fertile age group but also in peri and postmenopausal age groups in many aspects. Fibroids can significantly affect their quality of lives due to abnormal uterine bleeding, pelvic pain, pressure symptoms leading to bladder and bowel symptoms, and subfertility. The symptoms and effects of fibroids on a woman depends on the size or the volume, number, and the location of the of leiomyomas. Paul et al in his case series of uterine myomectomy has illustrated, pressure symptoms that negatively affect patient's quality of life, heavy uterine bleeding with failed medical therapy, infertility, rapid growth, and suspected sarcomas as indications for surgical management of fibroids ${ }^{\text {III }}$. Although there are several approaches of myomectomy including laparotomy, hysteroscopy, and MyoSure, Laparoscopic approach remains the commonly proposed mode of myomectomy with quicker recovery time, minimal postoperative pain, minimal blood loss and minimal postoperative intra-abdominal adhesions IV,V. Minimal access surgery remains the gold standard in many countries where the expertise is available. Even though there were many limitations for laparoscopic myomectomy in the past including the limitations caused by size and location of the fibroid, vascularity, and risk of intra-operative bleeding ${ }^{\mathrm{VI}} \mathrm{VII}$, with advancing technology and skilled surgeons there are virtually nil boundaries for the scope of laparoscopic approach in the contemporary.

Aims of our study were to analyze demographical, intraoperative and postoperative outcomes of 432 cases of laparoscopic myomectomy by a single surgeon in a tertiary center Sri Lanka.

\section{MATERIAL AND METHODS}

This is a retrospective analyze of laparoscopic myomectomies which were carried out by a single surgeon at professorial unit, Colombo South Teaching hospital, University of Sri Jayewardenepura Sri Lanka. Data was collected in a 10 years period between 2011 January to 2021 January form all patients who underwent laparoscopic myomectomy. Pre operatively all women were assessed by abdominal examination with or without bimanual examination and fibroids mapping was done by ultrasound scan. Patients with fibroids more than ten and fibroid size more than 32 weeks size were not selected for laparoscopic surgery due to technical difficulties. Findings suggestive of uterine malignancies were referred to gyane-oncological unit and excluded from the research. All patients were preoperatively assessed for fitness for major surgery and general anesthesia. Informed written consent was taken from all patients prior to surgery.

Surgical technique: All cases were done under general anesthesia, patient was positioned to modified loid Davidson 
position and bladder was empty using foley catheter. All patients were given intraoperative antibiotic prophylaxis and appropriate thromboprophylaxis. Laparoscopic entry was made through suprapubic or palmers point using Veress needle. Another two ipsilateral and one contralateral ancillary ports were used. All cases were performed using $10 \mathrm{~mm}$ telescope with Olympus laparoscopic stag. Intra-abdominal pressure of $15 \mathrm{mmhg}$ was maintain during the surgery. Vasopressin $20 \mathrm{IU}$ diluted in $200 \mathrm{ml}$ of normal saline were injected to myometrium to reduce intraoperative blood loss and laparoscopic myoma screw was use to manipulate uterus by the assistant. Monopolar diathermy was used for initial incision and bipolar diathermy was used for subsequent dissection and achieving haemostasis at the setting of 45 watts cutting and 45 watts coagulation. Additionally laparoscopy scissor and grasper were used and no other advanced energy devices were used for entire population. Myometrial defect was repaired using polyglactin layer by layer according to thickness of defect. However practice changed to use of barb sutures since 2015 from its introductions. Specimens were retrieved by electro-mechanical morcellation through lateral port. With the evidence of electro-mechanical fibroid morcellation complications, practice is changed to hand morcellation through $4 \mathrm{~cm}$ size suprapubic port with wound protector/ retractor.

Data were collected from patient database, hospital records and histopathology data base. All data were cross check by name and hospital register number to avoid duplication. Data were collected according to demographical details including age, BMI, parity and past surgical histories, myoma details including size, type, site and number, intraoperative details and postoperative details. Data were entered in Microsoft EXEL spread sheet and adhered to best clinical practice to ensure confidentiality. Ethical approval was taken from local ethics committee. However full ethical approval was not required as this was evaluation of ongoing practice. SPSS version 28 was used for data analyze. Descriptive analysis was performed in all data and relationship between myoma characteristics and surgical outcomes were assessed using $t$ test. $P$ value $<.05$ consider as significant.

\section{RESULTS}

There are four hundred and thirty two patients under went laparoscopic myomectomy during period of year 2010 to year 2021. Mean age of the population is 35.5 years (SD 6.083) Majority of the population (67\%) were nulliparous. $13.4 \%$ had history of past laparoscopic surgeries, $15.7 \%$ and $2.1 \%$ had history of past transverse suprapubic laparotomy and midline laparotomy respectively. Regarding indication for surgery, $192(44.4 \%)$ patients had pressure symptoms, 137 ( $31.7 \%)$ patients presented with heavy menstrual bleeding and 103 $(23.8 \%)$ patients had infertility. Number of surgeries per year has been gradually increased over period and there was 3 fold increment over last 5 years compare with initial five years.

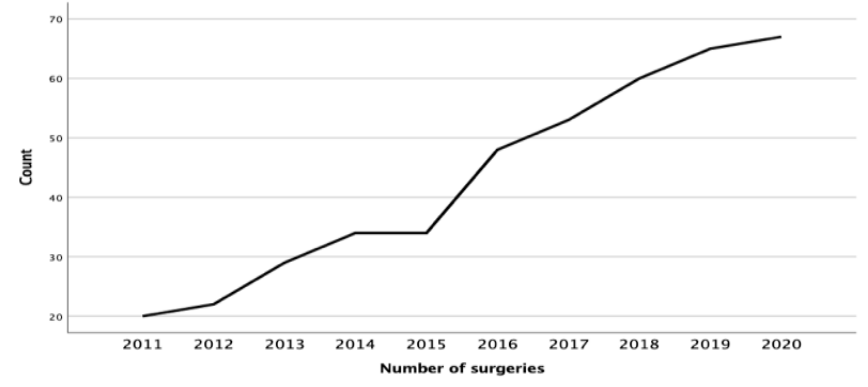

Figure 1: Number of surgeries according to the year. Number of surgeries has been incresed

Regarding fibroids characteristics, single fibroid found in 168 (38.9\%) patients, fibroids between 2-4 found in 199 (46.1\%) patients and fibroids 5-10 found in $65(15 \%)$ patients. In 159 $(36.8 \%)$ patients largest size of fibroid removed was $<8 \mathrm{~cm}$, in $169(39.1 \%)$ patients its was between $8 \mathrm{~cm}-12 \mathrm{~cm}$ and in $104(24.1 \%)$ patients it was more than $12 \mathrm{~cm}$. Considering the location of fibroid, $192(44.4 \%)$ patients had anterior wall, $125(28.9 \%)$ in posterior wall, $87(20.1 \%)$ in fundal, 21 $(4.1 \%)$ in broad ligament and other locations in $7(1.6 \%)$ patients. With regard to location, intramural fibroids identified in 196 patients (45.4\%), subserosal in 136 (31.5\%), submucosal in $75(17.4 \%)$ and pedunculated in $22(5.1 \%)$ patients.

Mean intraoperative blood loss was $159.4+/-68.03 \mathrm{ml}$, mean operative time was $124+/-49.6$ minutes. However blood loss and operative time varies according to size, number and location of fibroids.

Tables1: Comparison of fibroids number and size with surgical out comes

\begin{tabular}{|c|c|c|c|c|}
\hline & $<8 \mathrm{~cm}$ & $8 \mathrm{~cm}-12 \mathrm{~cm} 1$ & $>12 \mathrm{~cm}$ & $\mathrm{P}$ value \\
\hline $\begin{array}{c}\text { Mean blood } \\
\text { loss }(\mathrm{ml}) \\
\text { Operative time } \\
(\mathrm{min})\end{array}$ & $\begin{array}{c}115.25 \\
92.23\end{array}$ & $\begin{array}{l}152.4 \\
122.1\end{array}$ & $\begin{array}{c}238.27 \\
178.9\end{array}$ & $\begin{array}{l}<0.001 \\
<0.001\end{array}$ \\
\hline & 1 fibroid & 2-4 fibroids & 5-10 fibroids & $P$ value \\
\hline $\begin{array}{c}\text { Mean blood } \\
\text { loss(ml) } \\
\text { Operative time } \\
\text { (min) }\end{array}$ & $\begin{array}{c}122 \\
90.8\end{array}$ & $\begin{array}{l}166.5 \\
135.1\end{array}$ & $\begin{array}{c}234 \\
179.5\end{array}$ & $\begin{array}{l}<0.001 \\
<0.001\end{array}$ \\
\hline
\end{tabular}

Table 2: Comparison between fibroid type and location with surgical outcomes

\begin{tabular}{|c|c|c|c|c|c|c|}
\hline & Anterior & Posterior & fundal & $\begin{array}{c}\text { Broad } \\
\text { ligament }\end{array}$ & other & $\begin{array}{c}\mathrm{P} \\
\text { value }\end{array}$ \\
\hline $\begin{array}{c}\text { Mean blood } \\
\text { loss }(\mathrm{ml})\end{array}$ & 163 & 170 & 145 & 127 & 117 & .006 \\
\hline $\begin{array}{l}\text { Operative time } \\
\text { (min) }\end{array}$ & 125.9 & 133.6 & 115.8 & 113.5 & 80 & .008 \\
\hline & $\begin{array}{c}\text { Sub } \\
\text { Mucosal }\end{array}$ & $\begin{array}{c}\text { Intra } \\
\text { mural }\end{array}$ & $\begin{array}{c}\text { Sub } \\
\text { serosal }\end{array}$ & other & & $\begin{array}{c}\mathrm{P} \\
\text { value }\end{array}$ \\
\hline $\begin{array}{c}\text { Mean blood } \\
\text { loss }(\mathrm{ml})\end{array}$ & 139 & 163.1 & 162.3 & 95 & & .008 \\
\hline $\begin{array}{l}\text { Operative time } \\
\text { (min) }\end{array}$ & 90.8 & 135.1 & 179.5 & 60 & & .210 \\
\hline
\end{tabular}


There were no intraoperative complications in $99.5 \%$ cases. There was a one bladder injury in a patient with past laparotomy and one intraoperative blood transfusion. 358 (82.9\%) patients were discharged withing first 24hours of post-op period. $16.4 \%$ were discharged within first 48 hours and only 3 patents $(0.7 \%)$ kept up to 72 hours of period. There were no major postoperative complications. However two patients received blood transfusion, 8 patients developed febrile morbidity and 13 patients stayed in ward additional 24 hours due to pain. There were no cases required to conversion to laparotomy. All specimen histology reported as benign. Disseminated leiomyomatosis or parasitic myomas were not reported in any case during follow up.

Not only total number but also number of complicated surgeries have been increased over past 10 years period of time. Majority of surgeries with fibroid size $>12 \mathrm{~cm}$ were performed during last 5 years.(figure 2). Despite the complexity of surgeries and change of specimen retrieval method, operative time, blood loss, intraoperative and postoperative complications were not changed.

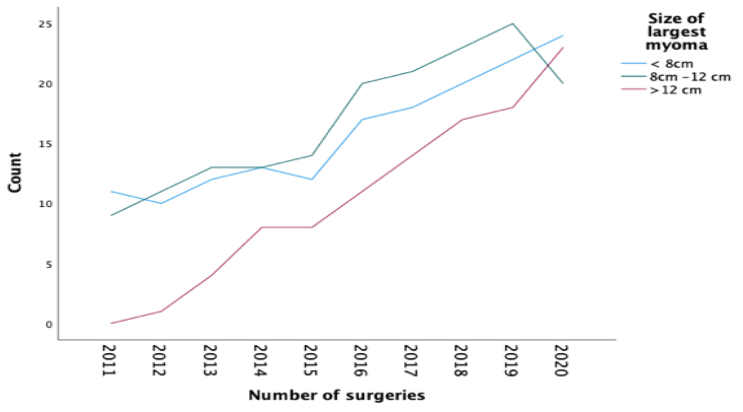

Figure 2: Size of the largest fibroid operated according to year. More complex and larger fibroids were operated with the time

\section{DISCUSSION}

Myomectomy is the most common procedure for symptomatic fibroids in reproductive age women. It can be done as open surgery, laparoscopically or hysteroscopically. Laparoscopic approach has many advantages including minimal blood loss, reduced requirement of post op analgesia, short hospital stay, minimal adhesion formation, early return to activities and better cosmetic outcome $\mathrm{VIII-X}^{\mathrm{X}}$. However there are limitations associated with laparoscopic approach such as prolog operative time, risk of convert to laparotomy, risk of reopening and complication related to specimen retrieval ${ }^{\mathrm{XI}-\mathrm{XIV}}$. Mais et al. ${ }^{\mathrm{XV}}$ shows that there is no significant difference in between open myomectomy and laparoscopic myomectomy in terms of bleeding and operative time. Hysteroscopic myomectomy is the choice of surgery for FIGO type 0,1 and 2 myomata. XVI,XVII.

This is the largest study of laparoscopic myomectomy reported in Sri Lanka. All surgeries were performed by experienced consultant gynaecolgist and assisted by a senior trainee. Our population mean age is 35.5 years and majority are nulliparous which are similar findings when compare with other case series. In our study total 1285 fibroids were removed and largest one is $30 \mathrm{~cm}$ (range $4 \mathrm{~cm}-30 \mathrm{~cm}$ ). However total number of fibroids more than 10 in a single patients were not selected for laparoscopy as it is associated with risk of incomplete removal of all fibroids and prolog operative time. Historically fibroid size less than $8 \mathrm{~cm}$ and two or less total fibroids were selected for laparoscopy

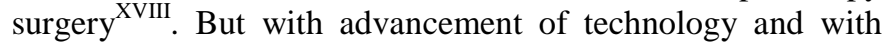
more surgical skills, these boundaries has been overcome. When reviewing literatures, average number of fibroids were removed range from 1- 4 and largest size of fibroid removed range from $5 \mathrm{~cm}-20 \mathrm{~cm}$.

Average operative time in our sample is 124.8 minute. Main factors determine the operative time were size of fibroid and number of fibroids. (table 1). This findings are compatible

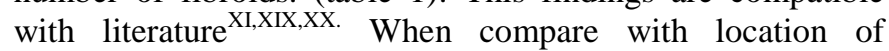
fibroids, posterior wall fibroids and broad ligament fibroids consumed more operative time than others. However it is not statistically significant when logistic regression done for size and number of fibroids . (p-0.172) prolonged operative time did not impact on surgical out comes in terms of hospital stay and blood transfusion. However there is a statistical significance association with postoperative pain $(\mathrm{p}<.001)$ and febrile morbidity $(\mathrm{p}<.001)$. Change the practice of specimen retrieval technique from electro-mechanical morcellation to hand morcellation through suprapubic port with wound protector/ retractor did not affect to surgical outcomes in terms of operative time, hospital stay, and additional requirement of analgesia.

Mean estimated blood loss in our population was $159.4 \mathrm{ml}$ (SD 68.03) which is comparable with literature XI,XIX-XXI. Three patients required blood transfusion. Size of the largest fibroid and number of fibroids are main determinant factors for intraoperative blood loss. Use of intraoperative vasopressin and achieving proper surgical plain are important factors to reduce blood loss. However there were no relationship between blood loss and location of fibroids.

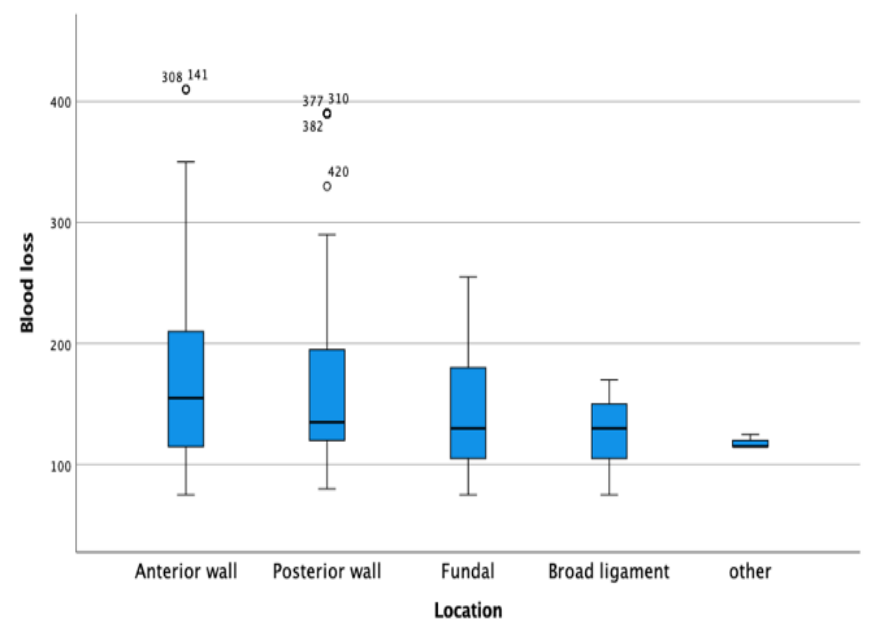




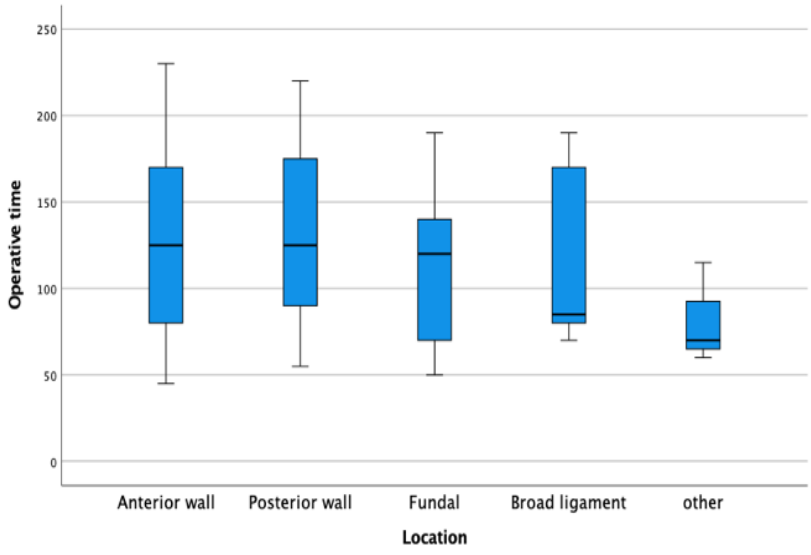

Figure 3: Operative time and Intra-operative blood loss according to location of fibroids

Overall complication rate in our population is $5.4 \%$ which include blood transfusion $(0.5 \%)$, febrile morbidity $(1.9 \%)$ and postoperative pain which required additional analgesia (3\%). These finding are compatible with previous studies. According to literature, conversion rate of laparoscopy to laparotomy range from $0.1 \%$ to $29 \%$. Main contributing factors are size of the fibroid, location and number ${ }^{\text {III,XXII,XXIII }}$. With good case selection and increasing experience with expertise contributed to bring down conversion rate to zero in our study despite of tackling larger size of fibroids and greater number of fibroids. Majority of patients were discharged within first 24 hours following surgery which is compatible with other studies $\mathrm{XI}, \mathrm{XX}, \mathrm{XXI}, \mathrm{XXIV}$. Operative time and duration of hospital stay has significant association ( $\mathrm{p}$ $<.001$ ). however location of fibroid or type of fibroid did not have any impact on duration of hospital stay.

With the new evidence, FDA discourage use of electro mechanical morcellation from $2014{ }^{\mathrm{XxV}}$. Our new technique of hand morcellation through suprapubic port with wound protector has better outcomes without compromising operative time, additional need of postoperative analgesia, wound infection or hospital stay. There were no single case of dissemination of fibroids were reported.

\section{CONCLUSION}

In experienced and expert hand, laparoscopic myomectomy is a safer procedure with good surgical outcomes and low complication rate. Operative time and blood loss mainly associated with size of largest fibroid and number of fibroids. Open myomectomy may benefit for number of fibroids $>10$ when considering completeness of surgery. Hand morcellation through suprapubic port is a safe and effective method of specimen retrieval.

\section{REFERENCES}

[1] Baird DD, Dunson DB, Hill MC, Cousins D, Schectman JM (2003) High cumulative incidence of uterine leiomyoma in black and white women: ultrasound evidence. Am J Obstet Gynecol 188(1):100-107.

[2] Walid MS, Heaton RL. Laparoscopic extirpation of a 3-kg uterus. Arch Gynecol Obstet 2009; 279:607-608.
[3] Paul GP, Naik SA, Madhu KN, Thomas T (2010) Complications of laparoscopic myomectomy: a single surgeon's series of 1001 cases. Aust N Z J Obstet Gynaecol 50(4):385-390.

[4] Sami Walid M, Heaton RL (2011) The role of laparoscopic myomectomy in the management of uterine fibroids. Curr Opin Obstet Gynecol 23(4):273-277.

[5] Litta P, Fantinato S, Calonaci F, Cosmi E, Filippeschi M, Zerbetto I et al (2010) A randomized controlled study comparing harmonic versus electrosurgery in laparoscopic myomectomy. Fertil Steril 94(5):1882-1886.

[6] Dubuisso JB, Fauconnier A, Babaki-Fard K, Chapron C (2000) Laparoscopic myomectomy: a current view. Hum Reprod Update 6(6):588-594.

[7] Glasser MH (2005) Mini laparotomy myomectomy: a minimally invasive alternative for the large fibroid uterus. J Minim Invasive Gynecol 12(3):275-283.

[8] Dubuisson JB, Fauconnier A, Chapron C, Kreiker G, Nörgaard C (1998) Second look after laparoscopic myomectomy. Hum Reprod 13(8):2102-2106

[9] Bulletti C, Polli V, Negrini V, Giacomucci E, Flamigni C (1996) Adhesion formation after laparoscopic myomectomy. J Am Assoc Gynecol Laparosc 3(4):533-536

[10] Jin C, Hu Y, Chen XC, Zheng FY, Lin F, Zhou K et al (2009) Laparoscopic versus open myomectomy-a meta-analysis of randomized controlled trials. Eur J Obstet Gynecol Reprod Biol 145(1):14-21

[11] Sizzi O, Rossetti A, Malzoni M, Minelli L, La Grotta F, Soranna $\mathrm{L}$ et al (2007) Italian multicenter study on complications of laparoscopic myomectomy. J Minim Invasive Gynecol 14(4):453462

[12] L andi S, Zaccoletti R, Ferrari L, Minelli L (2001) Laparoscopic myomectomy: technique, complications, and ultrasound scan evaluations. J Am Assoc Gynecol Laparosc 8(2):231-240

[13] Falcone T, Parker WH (2013) Surgical management of leiomyomas for fertility or uterine preservation. Obstet Gynecol 121(4):856-868

[14] Kho KA, Nezhat C (2009) Parasitic myomas. Obstet Gynecol 114(3):611-615

[15] Mais V, Ajossa S, Guerriero S, Mascia M, Solla E, Melis GB (1996) Laparoscopic versus abdominal myomectomy: a prospective, randomized trial to evaluate benefits in early outcome. Am J Obstet Gynecol 174(2):654-658

[16] Saccardi C, Conte L, Fabris A, De Marchi F, Borghero A, Gizzo $S$ et al (2014) Hysteroscopic enucleation in toto of submucous type 2 myomas: long-term follow-up in women affected by menorrhagia.J Minim Invasive Gynecol 21(3):426-430

[17] L itta P, Conte L, De Marchi F, Saccardi C, Angioni S (2014) Pregnancy outcome after hysteroscopic myomectomy. Gynecol Endocrinol 30(2):149-152

[18] Dubuisson J-B, Chapron C, Levy L (1996) Difficulties and complications of laparoscopic myomectomy. J Gynecol Surg 12(3):159-165

[19] Bean EMR, Cutner A, Holland T, Vashisht A, Jurkovic D, Saridogan E (2017) Laparoscopic myomectomy: a single-center retrospective review of 514 patients. J Minim Invasive Gynecol 24(3):485-493

[20] Sinha R, Hegde A, Mahajan C, Dubey N, Sundaram M (2008) Laparoscopic myomectomy: do size, number, and location of the myomas form limiting factors for laparoscopic myomectomy? J Minim Invasive Gynecol 15(3):292-300

[21] Sandberg EM, Cohen SL, Jansen FW, Einarsson JI (2016) Analysis of risk factors for intraoperative conversion of laparoscopic myomectomy. J Minim Invasive Gynecol 23(3):352357

[22] Ribeiro SC, Reich H, Rosenberg J, Guglielminetti E, Vidali A (1999) Laparoscopic myomectomy and pregnancy outcome in infertile patients. Fertil Steril 71(3):571-574

[23] Marret H, Chevillot M, Giraudeau B (2006) Factors influencing laparoconversions during the learning curve of laparoscopic myomectomy. Acta Obstet Gynecol Scand 85(3):324-329

[24] Seracchioli R, Rossi S, Govoni F, Rossi E, Venturoli S, Bulletti C et al (2000) Fertility and obstetric outcome after laparoscopic 
International Journal of Research and Innovation in Social Science (IJRISS) |Volume V, Issue XI, November 2021||ISSN 2454-6186

myomectomy of large myomata: a randomized comparison with abdominal myomectomy. Hum Reprod 15(12):2663-2668

[25] FDA. UPDATED Laparoscopic uterine power morcellation in hysterectomy and myomectomy: FDA safety communication (https://wayback.archive-it.org/7993/

$20161023125535 /$

http://www.fda.gov/NewsEvents/Newsroom/

PressAnnouncements/ucm393689.htm). Accessed 1 Jan 2017 